\title{
Balance patriótico. A propósito de la balanza huidobriana
}

\author{
Balance patriótico. \\ About the Huidobrian balance \\ Juan D. Cid Hidalgo \\ https://orcid.org/0000-0001-7651-6247 \\ Marisol Castro \\ https://orcid.org/0000-0003-3907-6195 \\ Valentina Albornoz \\ https://orcid.org/0000-0002-3365-4890 \\ Universidad de Concepción, Región del Bio Bio, Chile \\ Contacto: jdcid@udec.cl
}

\begin{abstract}
Resumen
En este artículo analizamos la imagen de nación que construye Vicente Huidobro a lo largo de la obra ensayística Balance Patriótico y que tiene como mayor característica la enfermedad. El imaginario creado por el autor fue escrito en el primer cuarto del siglo XX y se enmarca en una época de reevaluación de la imagen de nación. El ensayo deja en evidencia la existencia de un Chile dividido entre la luz del progreso y sus implicancias negativas.
\end{abstract}

Palabras clave: Vicente Huidobro; Nación; Imaginario; Infame; Ciudadano; Comunidad.

\begin{abstract}
In this Article we analyzed the way Vicente Huidobro built the nation as a concept in his essay Balance Patriotico and its major characteristic, illness. The work built by the author was written in the first quarter of the 20th century and it is framed in a period of reevaluation of the way the nation was seen in those days. The essay shows that Chile was divided between the light of progress and its negatives implications.
\end{abstract}

Keywords: Vicente Huidobro; Nation; Imaginary; Infamous; Citizen; Community 


\section{Introducción}

El ensayo Balance Patriótico (1925), del destacado poeta vanguardista chileno Vicente Huidobro, se concibe en una época conmocionada y convulsa, fundamentalmente por la fuerte crítica a la nación emergente. Ello a partir del modelo del ensayo, que ironiza y pone en tela de juicio las falsas imágenes nacionales que se esparcen por los medios oficiales, perspectiva que le valió no pocos detractores al poeta, que apenas seis años después publicaría Altazor (1931), una de las obras poéticas fundamentales del siglo XX.

Si revisamos brevemente el marco histórico en que se inscribe el ensayo, tendríamos que señalar que en la primera mitad del siglo XX comienza a instalarse una lógica económica neoliberal ${ }^{1}$ que posibilita muchos de los abusos, ventajas y aprovechamientos de los grupos de poder político sobre las capas populares. Gustavo Celedón en "Precio y desprecio: economía y amor propio" (2013), aclara el contexto económico en el que se desarrolla el país en este período:

Esa inercia de un Chile del siglo XIX y primera mitad del siglo XX, encuentra su modernización en la economía neoliberal. Esta economía no hace sino garantizar todo aquello que señala Huidobro. Circuita el desprecio por quien, en las afueras de la célula, se las arregla mejor con el mundo [sic]. Por quien, a fin de cuentas, tiene el talento que esta economía, en clave-desprecio, traduce o convierte en capital, en habilidades de esto o de otro, en publicaciones indexadas, en condecoraciones múltiples. (p. 184)

La plutocracia venía de regirse en otros términos y con distintos métodos, los cuales comienzan a instaurar una modernización propia de los estados extranjeros, la misma que traería fuertes repercusiones en el imaginario nacional. Así las identidades creadas sobre la base de las actividades laborales o las costumbres propias de una nación en formación se empezarían a mezclar hasta existir difusos márgenes entre los identitarios nacionales, identidades que según el autor constituyen un paisaje decadente.

Las características que rondan la configuración de identidades nacionales son la hibridez y el desorden, peculiaridades propias de un género textual que, se- 
gún Mario Góngora, no puede ser incluido dentro de "la historia política, social, económica o cultural”, sino que son historias de una 'noción' (1981, p. 5). Así, el Balance Patriótico termina formando parte de un conjunto de ensayos que el historiador utiliza como muestras para construir la noción general de un periodo histórico:

Se trata aquí esta historia en forma de "ensayos", esto es, en una forma libre y abierta, sin ninguna pretensión de sistema, ni con las exigencias rígidas de una monografía. Un ensayo histórico es también una investigación, pero su objetivo es hacer considerar o mirar algo, sin tratar de demostrarlo, paso a paso. (Góngora, 1981, pp. 5-6)

Los gritos desgarradores de denuncia suelen ser erráticos, por tanto, resulta naturalmente complejo encasillarlos dentro de un solo sentimiento; esto es precisamente lo que nos sucede con Huidobro: su enojo, su impotencia, sus miedos le impiden utilizar un género raído por las antiguas convenciones literarias, necesita libertad para expresar sus sentimientos. Es precisamente aquí cuando Balance Patriótico se convierte en el lienzo para construir o deconstruir, dependiendo de la perspectiva del crítico o lector, los pilares mal afirmados de la nación chilena. Huidobro nos habla de una nación enferma y en ella incluye una serie de estereotipos rechazados por los ciudadanos del país. El poeta se encarga, precisamente, de resaltar los matices ocultos por las generaciones fundacionales de la nación chilena. El antropólogo Yanko González, en su apartado “"Que los viejos se vayan a sus casas' Juventud y vanguardias en Chile y América latina” (2002), apunta que:

En gran parte de América Latina dicho trayecto está signado, por un parte, por las luchas entre la "fronda" aristocrática, oligárquica, católica y conservadora, que frenaba tercamente la expansión de la modernidad (económica y cultural); $\mathrm{y}$, por otra, por un sector mesocrático y obrero en continuo crecimiento, que impugnaba la re- 
dirección de la modernidad, democratizando la sociedad a partir de cambios sociales y culturales profundos, criticando la sola "modernización de las apariencias". (p. 61)

Al parecer los escritos de Huidobro, tal como los escritos de la llamada generación descristalizadora (Promis, 1977), se dedican a describir y evidenciar estereotipos para así desgarrar fuertemente las ilusiones de progreso que la clase alta pretendía propagar en el país y en el resto del globo. Chile crecía, pero desigualmente hacia el futuro. Huidobro se convierte en portavoz de los olvidados, de los ocultos residuos nacionales que terminan siendo víctimas de una justicia parcial ${ }^{2}$. El destacado poeta toma el contexto físico de los arrabales, retrata un conjunto de cuerpos enfermos, viciosos, y extrapola su imagen a la de una patria que se cae a pedazos. Balance Patriótico, en este sentido, es una cuenta pública coléricamente desnuda que deja en evidencia toda la vergüenza de un país cuyos destrozos son causa de la clase dirigente, grupo social que, aunque seguro de sí, no era más que una masa de seres ignorados por un mundo que olvidó a Chile sin nunca conocerlo realmente. Frente a esta situación, los intelectuales de la época —entre los que se cuenta el creacionista - parecen revelarse a través de la escritura. Así, surge un perfil de pensador que, en palabras de Francisco Javier Pinedo en "Apuntes para un mapa intelectual de Chile durante el centenario: 1900-1925” (2011):

Se trata de un pensador que se ve a sí mismo como la conciencia lúcida de la sociedad, pues cree saber lo que sucede en ella y poseer la solución para los problemas que denuncia; un pensador que opina desde sí mismo y para un país que es el suyo. Son pensadores que en sus obras intentan representar (criticar) al país completo: la clase alta, la media y la popular. (p. 30)

El poeta formó parte de una generación de intelectuales que evaluaban sinceramente la situación, grupo que "realizó un balance negativo del país, y que se le conoce como "Generación del Centenario"” (Pinedo, 2011, p. 30). Ello causó cierto resquemor entre los gobiernos de turno, de hecho, fueron bautizados de manera peyorativa "aguafiestas". Pinedo, en el artículo antes citado, señala al respecto: 
“Todo parecía funcionar bien. Mientras esto sucedía, los 'aguafiestas' ponían en evidencia las contradicciones y limitaciones de la sociedad chilena desde una mirada múltiple: nacionalista, antiliberal, socialista, anticlerical y antioligárquica, exigiendo una mayor participación del Estado en el desarrollo económico"

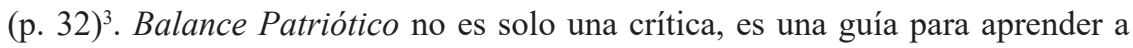
gritar las injusticias de un país que está carcomido por las desigualdades y que vive en la falsa ilusión de crecimiento. Un país que sigue las direcciones de otros más desarrollados, queriendo imitar sus costumbres, sin arreglar aquellas ataduras propias que nos mantienen en el subdesarrollo. Huidobro trata de desdibujar la historia nacional, crea una propia y se dibuja a sí mismo como un actor del cambio. María Paz Mira agrega:

A partir de este análisis, se percibe que su objetivo fue el de originar e implantar la necesidad de "crear realidades" en un mundo propio que representase al individuo a niveles estéticos y políticos. Esto, con el fin de alcanzar un auténtico concepto de patria y nación, sentimientos que según el poeta yacían olvidados en la sociedad de la época. Para lograr esto, según Huidobro, debía implementarse una "regeneración" nacional, ideal plasmado tácitamente en su "Balance Patriótico" y en términos más amplios en Acción, en donde se planteaba que la juventud pedía "a gritos un Chile nuevo y grande". Huidobro reconoció en esta juventud "limpia y fuerte", la capacidad para llevar a cabo una "política realista y de acción", por lo que el objetivo crucial del poeta en 1925, no fue otro que el de acabar y extirpar de raíz a los "viejos" de los que emanaba una "crisis de hombres" debido a su "falta de alma”. (2008, pp. 40-41)

Por otro lado, debe recordarse que este ensayo fue publicado dentro de la revista Acción, fuente que, según Mariana Alvarado en su artículo "Ni aristócratas, ni rebeldes, ni tristes ni contentos: escritura y revistas literarias de Joaquín Edwards Bello, Teresa Wilms Montt y Vicente Huidobro" (2010), constituye un lugar para construir y cruzar líneas de pensamiento y difusión de los mismos. Huidobro ocupa la revista como una herramienta para una guerra que no tiene ganadores, solo perdedores conscientes del mal funcionamiento de un sistema que se cae a peda- 
zos. Las revistas permiten que autores divergentes tomen la tribuna que la prensa de la época había ensuciado con su falta de ética, siendo los guardaespaldas de las clases poderosas, en otras palabras, aquellas revistas sostuvieron la disidencia respecto de esa imagen país instalada por los poderosos y, por tanto, pretendía desenmascarar la vejez y el deterioro ético y moral de los gobernantes.

Mariana Alvarado, nuevamente recordando al sociólogo francés, señala:

Las revistas son, para Bourdieu (2005), bienes culturales que los productores que buscan posicionarse dentro del campo crean con el objetivo de aumentar su capital simbólico. Para Jacques Dubois (1988), las revistas son instancias institucionalizadoras. En tanto que Daphne de Marneffe (2007) y Paul Aron (1998) coinciden con la idea del "efecto red" de las revistas. Para nosotros, las revistas son un capítulo constructor del campo, por cuanto estas publicaciones son activadoras del espacio literario. Además, son lugares simbólicos de "visibilización" de nuevas subjetividades, a la vez que espacios de tomas de posición de los escritores y escritoras partícipes de ellas con la intención discursiva de contravenir su habitus e influir en las reglas del campo mismo. Por lo tanto, las revistas son la "trinchera" y a la vez el almácigo de nuevas sensibilidades que mutan a medida que van escribiendo la historia de la revista misma. (2010, p. 36)

El antropólogo Yanko González ahonda en el contexto de producción más que en los aspectos estéticos del ensayo, de esta manera vincula al autor con movimientos estudiantiles y con el militar revolucionario Marmaduque Grove. El texto señala:

En agosto de 1925, funda y dirige Acción. Diario de Purificación Nacional, que se financia gracias a la ayuda de oficiales jóvenes del ejército y la armada, dirigido por Marmaduque Grove (este último más tarde líder de la experiencia socialista chilena anterior a la Unidad Popular, cuya duración fue de 12 días). Su orientación es pro-militarista progresista y juvenil, solidarizando con los sectores más desposeídos y enarbolando la bandera de la "cuestión social". Sufre una serie de hostigamientos y ese mismo mes es agredido en dos oportunidades en las cercanías de su casa al denunciar actividades ilícitas del ámbito político-administrativo. (González, 2002, p. 20) 
Esto proviene principalmente del hecho de que Balance Patriótico representa una protesta ante una aristocracia y una clase política que no lo satisface. Entre las consecuencias de sus malas relaciones, Yanko González destaca la clausura de la revista Acción el 21 de noviembre. Sin embargo, Huidobro no da pie atrás y termina fundando otro periódico, esta vez, La reforma.

\section{Reflexiones en torno a una virulencia política literaria}

Balance Patriótico nace de la efervescencia política en una época en la cual la reflexión sobre la economía, la educación y las proyecciones a futuro eran la tónica. Hablamos pues de las reflexiones de países jóvenes, naciones que aún no descubrían o reconocían los rincones más oscuros de su identidad. Identidad que es caracterizada por ser portadora de una hibridez, condición generalizable a toda Latinoamérica y por supuesto a nuestro país, que posee una rica mezcla de culturas, ideas y sentires.

A raíz de la celebración del centenario de la nación, Vicente Huidobro se vio en la necesidad de hacer una recapitulación de la historia e identidad nacional; por consiguiente, necesitaba de un género joven, fuerte pero flexible para poder representar una nación que emergía de la decadencia y el aislamiento geográfico. Así nace Balance Patriótico, ensayo breve, ilustrativo y cruel sobre los vaivenes de una patria de la que el poeta se siente salvador.

El análisis de este ensayo seguirá la perspectiva de Benedict Anderson en Comunidades imaginadas y su definición de nación a partir de la idea de comunidad e imaginario social ${ }^{4}$. La célebre definición del crítico irlandés señala: “[...] propongo la definición siguiente de la nación: una comunidad política imaginada como inherentemente limitada y soberana" (1991 [1983], p. 23)5.

Los individuos que forman parte de la nación, aunque son incapaces de ver y conocer a todos los miembros de la comunidad, aún así los consideran connacionales y sienten cierta fraternidad o conciencia de bloque con ellos. En adelante, procuraremos identificar qué individuos son imaginados y cuáles son olvidados en el ensayo Balance Patriótico, seguimiento que nos permitirá tener un conocimiento de quiénes y cómo son los chilenos imaginados por el poeta y ensayista; 
si son blancos, mestizos, indígenas, varones, mujeres o inmigrantes y cómo convergen en la vida político-social del país.

Recordemos también que la nación es consecuentemente limitada, pues según Anderson (1991 [1983]) la comunidad no puede incluir a todos los miembros de la esfera terrestre, como tampoco pretende concretar tal hecho. Situación que difiere de las religiones, pues estas aspiran a ser difundidas por toda la humanidad para convertir a sus integrantes en correligionarios. En suma, el imaginario nación se extenderá desde una porción geográfica determinada e incluirá un número finito de connacionales. En el ensayo podremos reparar en estas características a partir de los nombres de los lugares, de los grupos étnicos, genéricos, políticos y/o sociales que se incluyen u omiten dentro de la obra.

En cuanto a la característica de "soberana", somos conscientes de que Chile no estaba relegado a un rey en el año 1925, cuando se escribió este ensayo, como lo estaba Anderson cuando redactó su definición. Sin embargo, el reino español al que estuvo subyugada la colonia dejó secuelas sobre esta nación incipiente, hecho que intentaremos identificar en la obra. Por otra parte, es necesario incluir a los poderes del Estado, ya que este posee autoridad sobre los connacionales. Tal hecho puede ser identificado dentro de Balance Patriótico a través de referencias a instituciones, personas particulares o referencias a la exmetrópoli o país colonizador, en este caso España. Creemos también que Europa evocará un pasado de sometimiento y deseo mimético al compararla con la nación o solo al admirar al viejo continente.

Respecto a la categoría de comunidad, Anderson señala que, aunque surjan inequidades y relaciones de sometimiento entre sus miembros, existirá una cierta unidad y familiaridad entre ellos. Esto podremos identificarlo a partir de las referencias pronominales y cómo estas incluyen a ciertos grupos humanos o dejan fuera otros. Esta categoría nos ayudará a comprender cómo convergen los habitantes del país en el imaginario del poeta.

A continuación, analizaremos Balance Patriótico teniendo en cuenta las categorías señaladas en los párrafos precedentes. 


\section{A.- Los imaginados, los olvidados, los omitidos}

Huidobro a modo de cuenta pública decide enumerar y desmentir todas aquellas falsedades que el país intentaba demostrar. Estas características de la patria propagadas por los políticos terminan por ser demolidas con esta desenfrenada cuenta pública que imagina ciudadanos diferentes a los que pueblan la historia dorada. Balance Patriótico, incluido en el apéndice del libro Ensayo histórico sobre la noción de estado en Chile de Mario Góngora (1981), retrata un paisaje decadente edificado a través de las siguientes palabras:

Un país que apenas a los cien años de vida está viejo y carcomido, lleno de tumores y de supuraciones de cáncer como un pueblo que hubiera vivido dos mil años y se hubiera desangrado en heroísmos y conquistas. Todos 1os inconvenientes de un pasado glorioso, pero sin la gloria. No hay derecho para llegar a la decadencia sin haber tenido apogeo. (Huidobro, 1981, p. 113)

Mientras en Chile se celebraban fiestas conmemorando el centenario, exhibiendo grandes avances y olvidando las realidades menos afortunadas que se escondían entre los escombros, la población nadaba en una quimera de riquezas y aristocracia blanca. Huidobro con una incipiente vocación política se empeña en retratar, de forma irónica y valiente, el lado silente de una nación. En la cita anterior, Huidobro describe de forma enérgica e iracunda una sociedad que ha adquirido todos los males de una aristocracia ya decadente, esto debido a la incesante táctica de imitación al continente europeo, desechando así toda muestra de sapiencia vernácula.

Uno de los primeros sujetos que utiliza Huidobro para desmontar el imaginario oficial y crear el propio es la figura del huaso, imagen supuestamente representativa del hombre rústico chileno. El huaso que se retrata en los cuadros de costumbres como símbolo de la inocencia, de la solidaridad y fortaleza robusta, además de ser morfológicamente descrito como blanco, de pómulos rosa y muy vigoroso, es relatado por el poeta como una estatua al arribismo, la charlatanería y la ignorancia identitaria. El párrafo siguiente retrata esta situación de vergüenza nacional: 
El huaso macuco disfrazado de médico que al descubrirse la teoría microbiana exclama: a mí no me meten el dedo en la boca; el huaso macuco disfrazado de filósofo que al oír los problemas del transformismo dice: a otro perro con ese hueso; el pobre huaso macuco disfrazado de artista o de político que cree que diciendo: no comprendo, mata a alguien en vez de hacer el mayor elogio. (Huidobro, 1981, p. 113-114)

Para Vicente la nación es joven y, por lo tanto, se encuentra desorientada al no aceptar sus raíces, al no reconocer su mestizaje. La ciudadanía vive a la deriva desde un punto de vista ideológico e intenta vivir con la "clase" de las viejas naciones; de esta forma, el chileno acaba por adoptar sus maneras. Por supuesto, aquella parodia de nación moderna solo crea falsas formas de pensar y de comportamiento, cayendo en una tragicomedia desbordante de mentiras y envidias. Una ficción que trae consecuencias graves para todo residuo nacional que no concuerda con la imagen de un Chile católico, blanco y criollo.

Un país que se jacta de sus grandes avances no puede aceptar el error como un componente de sus compatriotas; así el huaso, orgulloso de su testarudez, persiste con ideas mal construidas y erróneas, celebrando, en su propia opinión, el ahínco que lo caracteriza. No obstante, Huidobro reclama la falta de erudición del país utilizando una gama de preguntas retóricas que caen como yunque sobre la mente terca del fantasioso chileno de la época. El texto a este respecto es, como en tantos otros momentos, profundamente directo y categórico:

Por eso Chile no ha tenido grandes hombres, ni podrá tenerlos en muchos siglos. ¿Qué sabios ha tenido Chile? ¿Qué teoría científica se debe a un chileno? ¿Qué teoría filosófica ha nacido en Chile? ¿Qué principio químico ha sido descubierto en Chile? ¿Qué político chileno ha tenido trascendencia universal? ¿Qué producto de fabricación chilena o qué producto del alma chileno se ha impuesto en el mundo? (Huidobro, 1981, p. 114)

Chile no había incursionado en el ámbito científico: no existían teorías, ni estudios que permitieran reconocer su nación imaginada como un estado desarrollado y contribuyente al conocimiento y desarrollo humano universal. Para 
Huidobro, Chile era esclavo de una enferma mimesis hacia otras naciones. Por esta razón terminamos viviendo en un territorio regido por una inercia intelectual sin la más mínima muestra de raciocinio.

El poeta y ensayista se transforma en símbolo de un hombre cansado, un ser apestado de ver su tierra dormir complacida por sus anodinos avances; esto lo manifiesta a través de aquellas múltiples interrogantes que parecen no tener respuesta. Preguntas retóricas que nos hacen mirar la infectada herida. Empero, debe dejarse en claro que Huidobro no pierde esperanza en que la nación mejore, sigue aferrado a su madre agonizante, a pesar de que todas las señales le indican que ya es tarde.

El propio poeta anunció que: "Decir la verdad significa amar a su pueblo y creer que aún puede levantarse y yo adoro a Chile, amo a mi patria desesperadamente, como se ama a una madre que agoniza" (Huidobro, 1981, p. 114). Su crítica ulcerosa no es más que un llamado de atención, un remezón a mano firme para quitarles la modorra a sus compatriotas. El autor sueña con una nación que emerja con convicciones propias, con un alma: "Necesitamos lo que nunca hemos tenido, un alma. Basta repasar nuestra historia. Necesitamos un alma y un ariete, diré parafraseando al poeta íbero. Un ariete para destruir y un alma para construir" (Huidobro, 1981, p. 119).

En suma, Chile debía deconstruirse física e ideológicamente para poder aspirar a la sanidad del colectivo. Era necesario un ariete para destruir la puerta que los mantenía prisioneros en las letras resplandecientes de un ilusorio desarrollo. Por consiguiente, había que incluir a otros seres, no a los de manta flamante ni a los dueños de Chile. Hablamos de los pobres, de los sujetos que resultan incómodos de ver, a ese "sesenta por ciento de la raza, sifilítica. El noventa por ciento, heredo-alcohólicos (son datos estadísticos precisos); el resto insulsos y miserables a fuerza de vivir entre la estupidez y las miserias" (Huidobro, 1981, p. 113). La cita denota un apocalipsis nacional. Un cuerpo en crisis al borde del colapso: “[...] soñoliento y lánguido, arrastrando su cuerpo como un saco de pestes, su cuerpo gastado por la mala alimentación y carcomido de miserias y entre tanto la sombra de Francisco Bilbao llora de vergüenza en un rincón. ¿Qué hombre ha sabido 
sintetizar el alma nacional?” (Huidobro, 1981, p. 114). Esta nación instituyente sobrevive en harapos, hay más hombres que aquellos aristócratas dueños de bancos o viñas, hay personas que viven entre los residuos que esparcen los grandes.

Hasta ahora hemos descrito a la nación instituyente de Balance Patriótico como un imaginario acogedor en lo que refiere a los grupos marginados, al pobre, al enfermo, al roto; sin embargo, su imaginario no es totalmente inclusivo. Al señalar lo último nos referimos a que el autor utiliza solo artículos y sustantivos masculinos para evocar a los connacionales. Creemos que la mujer no fue exiliada del discurso por un repudio a su género, sino por una falta de conciencia ante esta. La explicación está en que el sujeto no puede imaginarla como parte del contexto político porque la cultura cívica solo consideraba como ciudadanos a los hombres alfabetizados mayores de 21 años; por lo tanto, la mujer no formaba parte de un discurso político que posicionaba al emisor como un iluminador ante tanta miseria.

Otros olvidados son los pueblos originarios. Claro está que tampoco eran parte de los ciudadanos, pues en aquella época la alfabetización no estaba difundida dentro de las zonas rurales en que estos habitaban; no obstante, el marginarlos de un discurso que habla sobre identidad nacional resulta complejo. Es decir, el aborigen no sería connacional para el sujeto que imagina, la razón la desconocemos; podría ser vergüenza, indiferencia o aversión, más no tenemos cómo saberlo. Lo claro es que los indígenas de nuestro país no se encontraban dentro de su lector ideal. Por tanto, era de esperar que Huidobro no añadiera como sujeto de derecho a las minorías étnicas.

\section{B.- El territorio, los límites, los otros lugares}

El territorio en el que se construye la nación tiene gran importancia, pues este contribuye a la consolidación de la identidad de los connacionales. Ernest Renan se refiere a esto en su ensayo “¿Qué es una nación?” (2004 [1882]):

La geografía, lo que se llama las fronteras naturales, contribuye considerablemente por cierto en la división de las naciones. La geografía es uno de los factores esenciales de la historia. Los ríos han conducido a las razas; las montañas las 
han detenido. Los primeros han favorecido los movimientos históricos; las segundas los han limitado. ¿Se puede decir, sin embargo, como lo creen ciertos partidos, que los límites de una nación están escritos sobre el mapa y que esta nación tiene el derecho de apropiarse lo que sea necesario para redondear ciertos contornos, para alcanzar tal montaña, tal río, a los cuales se atribuye una especie de facultad delimitadora a priori? No conozco doctrina más arbitraria ni más funesta. Con ella se justifican todas las violencias. (p. 10)

En un país tan fragmentado, tanto por la distancia, por los accidentes geográficos, como por los sentires y los modos de vida, resulta complejo hacer una síntesis que retrate aquella gama de costumbres construida por años a partir de imposiciones arbitrarias. Por ello, el ensayo resulta ser el género más apto para soportar toda la hibridez de un país que quiere tener más de los otros que de sí mismo. Además, este mismo género permite, con ayuda de la lengua, deconstruir la nación instituida:

Tenemos fama de imperialistas y todo el mundo nos mete el dedo en la boca hasta la campanilla. Nos quitan la Patagonia, la Puna de Atacama, firmamos el Tratado de Ancón, el más idiota de los tratados, y nos llaman imperialistas.

Advirtiendo de pasada que hubo un ministro de Chile en Argentina, el ministro Lastarria, que tuvo arreglado el asunto de la Patagonia, dejando a la Argentina como límite sur el Río Negro, y este ministro fue retirado de su puesto por antipatriota. Tal ha sido siempre la visión de nuestros gobernantes. (Huidobro, 1981, p. 119)

El pasaje anterior, lleno de nostalgia por la pérdida de territorios que imagina el individuo desde su vivienda, remite a una nación en formación, a una "nación en pañales" que se remese en un acomodamiento de los músculos constitutivos. El mapa de la nación es inestable, por lo tanto, la idea de esta acaba por ser vacilante. Por consiguiente, hay rencor, un rencor similar al que siente el humano cuando se le extirpa un miembro. Chile es un parapléjico con ganas de ser atleta. La nación instituida tiene forma de imperio, la nación instituyente de Huidobro es la de una aldea de trashumantes.

Por otro lado, hablamos de una tierra que es trabajada arduamente por los connacionales; sin embargo, termina irremediablemente siendo explotada por pode- 
rosos empresarios extranjeros. Es así como la nación enferma descrita por Huidobro es despojada de sus materias primas, de toda su fortuna natural hasta que solo queda un esqueleto, un pedazo de tierra lleno de perforaciones por el metal extranjero que desgarra las entrañas del cadáver nacional. Las siguientes palabras encarnan esta situación imaginada y digerida por la potente pluma del poeta:

\begin{abstract}
Y así vienen, así se dejan caer sobre nosotros; las inmensas riquezas de nuestro suelo son disputadas a pedazos por las casas extranjeras y ellos viendo la indolencia y la imbecilidad troglodita de los pobladores del país, se sienten amos y les tratan como a lacayos, cuando no como a bestias. Ellos fijan los precios de nuestra materia prima al salir del país y luego nos fijan otra vez los precios de esa misma materia prima al volver al país elaborada. (Huidobro, 1981, pp. 114-115) ${ }^{6}$
\end{abstract}

No obstante, el pueblo chileno no merece ser categorizado en el grupo de los inocentes, y este es el momento en que se produce la autocrítica de la nación. Huidobro trata a Chile como una masa inerte que se deja manosear por la ambición de los otros, es decir, como un grupo humano sin identidad fija, un grupo fatalista incapaz de racionalizar frente a lo que ocurre en sus narices. Chile subsidia su tierra de a poco mientras el pensamiento crítico se deshace entre tratados empresariales: "No es culpa del extranjero que viene a negocios en nuestra, tierra. Se compra lo que se vende; en un país en donde se vende conciencias, se compra conciencias. La vergüenza es para el país. El oprobio es para el vendido, no para el comprador" (Huidobro, 1981, p. 115).

El extranjero limítrofe es visto como un par que avanza más rápido; empero, esta velocidad no es causada por una superioridad biológica o material, sino por la ineficiencia de la autoridad nacional ya que esta atenta contra la geografía chilena con más fuerza e inclemencia que un fuerte sismo natural. Chile se queda atrás por causa de los poderosos, nueva relación causa-efecto que sumerge a los pobres y menesterosos gracias a la ambición de una plutocracia indigna y llena de modorra. El ensayo describe punzantemente lo señalado:

Los países vecinos pasan en el tren del progreso hacia días de apogeo y de gloria. El Brasil, la Argentina, el Uruguay 
ya se nos pierden de vista y nosotros nos quedamos parados en la estación mirando avergonzados el convoy que se aleja. Hasta el Perú hoy es ya igual a nosotros y en cinco años más, en manos del dictador Leguía, nos dejará también atrás, como nos dejará Colombia, que se está llenando de inmigrantes europeos.

¿Y esto debido a qué? Debido a la inercia, a la poltronería, a la mediocridad de nuestros políticos, al desorden de nuestra administración, a la chuña de migajas y, sobre todo, a la falta de un alma que oriente y que dirija (Huidobro, 1981, p. 117)

En conclusión, el individuo imagina una comunidad limitada entre una fructífera geografía que acaba por convertirse en un cadáver gracias a la mala administración de los gobernantes que no se inmutan mientras las rapaces entidades extranjeras se llevan el alma y escupen despojos, una zona económica exclusiva de todos los que no son chilenos. El imaginario geográfico se reduce a un "Chile que aparece como un inmenso caballo muerto, tendido en las laderas de los Andes bajo un gran revuelo de cuervos" (Huidobro, 1981, p. 115).

\section{C.- La soberanía, los poderosos pasados, los presentes, las secuelas y las heridas}

Ya no es época de reyes, Chile ya no es una colonia, pero aun así queda algo de ella. La principal repercusión de este sentimiento se ve en las reacciones de los poderes del Estado en los cuales recae la soberanía de la prole hambrienta y de las tierras fértiles que acaban por convertirse en peladeros. Es así como los componentes de la clase política del país, al igual que en El roto de Edwards Bello, son tratados como personajes sin ética, guiados por una avaricia incontrolable y por el hambre de poder que contrasta con una ignorancia sin límites y la desorientación del político primerizo:

Y esos prohombres de la política chilena, esos señores que entregan el país maniatado por una sonrisa de Lord Curzon y unos billetes de Guggenheim, no se dan cuenta que cada vez que esos hombres les dan la mano, les escupen el rostro. ¡Qué desprecio deben sentir los señores del cobre por sus abogados! (Huidobro, 1981, p. 115) 
El aprecio casi llevado a la idolatría de la raza europea, tan alejada de la nuestra, lleva a los empresarios y clase política a regalar el país por unos centavos, con tal de estar cerca de ellos. Ese arribismo de "raza" incesante que los hace renegar de la suya propia proviene de los primeros días de la nación e incluso antes. Las consecuencias de esas palabras llevan a la clase dirigente a venderse cual meretriz, con tal de convivir en equidad con ellos. Huidobro se mofa de esta situación, la aborrece y se avergüenza al ver a un país dirigido por un grupo de zalameros idiotizados por los colores de piel, efecto que es causa de un territorio colonizado que debió subsistir ante la figura de un rey invisible que los vigilaba desde el otro lado del océano. Hay una especie de orfandad que Eduardo Restrepo y Axel Rojas problematizan en su libro Inflexión Decolonial (2010) y que compendian en los siguientes términos:

El grueso de las narrativas históricas, sociológicas, culturales y filosóficas que circulan sobre la modernidad, incluso en sus versiones críticas, son el resultado de enfoques eurocentrados e intra-modernos (cfr. Escobar 2003). Es decir, de un lado suponen que la modernidad se origina en Europa y que de allí es exportada o se difunde, con mayor o menor éxito, a otros lugares del mundo y, de otro, asumen que la modernidad se entiende desde problemáticas y categorías modernas. (p. 18)

$\mathrm{Al}$ perder la guía intelectual del viejo continente, Chile siente una desorientación patológica que se refleja en las decisiones del poder, tanto de la aristocracia de apellidos vinosos como de la plutocracia de apellidos bancosos. El poeta describe el actuar de ambas con los siguientes párrafos:

La primera giraba a todos los vientos como veleta loca, para caer luego en el mismo desorden y en la misma corrupción que atacara en el Gobierno derrocado, echando sobre las espaldas de un solo hombre culpas que eran de todos; pero más que de nadie, de aquellos que, en vez de ayudarle, amontonaban los obstáculos en su camino.

La segunda, hecha por un grupo de verdaderos idealistas, se diría que principia a desflecarse y a perder sus rumbos 
iniciales al solo contacto de la eterna lepra del país, los políticos viejos.

¿Hasta cuándo tendrán la ingenuidad de creer que esa gente va a enmendarse y cambiar de un solo golpe sus manías del pasado, arraigadas hasta el fondo de las entrañas, como quien se cambia un paletó? (Huidobro, 1981, p. 119)

Claramente, los políticos del país no están respondiendo ante las necesidades de una nación que crece; a diario ven cómo los derechos de los más desposeídos son evadidos ante las necesidades de las grandes empresas que se instalan en el país indiscriminadamente. Lo anterior nos hace rememorar las siguientes palabras de Michel Foucault en Genealogía del racismo (1996a) cuando apunta que “[...] el poder es esencialmente el que reprime; el poder reprime por naturaleza, a los instintos, a una clase, a individuos" (p. 24).

Para el ensayista existe una pérfida mafia administradora del patrimonio nacional, pues estos son tomados por ladronzuelos de la horrible estampa. De esta manera termina comparándolos con Francisco Falcato, conocido por su astucia y capacidad de burlar a las autoridades de la época en lo que respecta al robo de ganado, pero le otorga mayor superioridad a este que por lo menos tenía coraje ${ }^{7}$. En resumidas cuentas, el autor ha perdido su fe en los conductores de la nación y grita colérico por el cambio. Su Chile necesita un cambio de rumbo, pero para que esto ocurra se necesita gente nueva, se necesitan jóvenes mentes con ideas rebosantes de pasión, alejadas de las secuelas de una colonia perdida en el fin del mundo.

Este canto de la cólera del poeta también recae sobre el poder sancionador del país: la justicia. Huidobro no encuentra una diferencia en el modo de actuar de este poder que es imprescindible para la buena marcha del país. Él dice que:

La Justicia de Chile haría reír, si no hiciera llorar. Una Justicia que lleva en un platillo de la balanza la verdad y en el otro platillo, un queso. La balanza inclinada del lado del queso.

Nuestra Justicia es un absceso putrefacto que empesta el aire y hace la atmósfera irrespirable. Dura o inflexible para los de abajo, blanda y sonriente con los de arriba. Nuestra Justicia está podrida y hay que barrerla en masa. Judas sentado en el tribunal después de la crucificación, acariciando en su bolsillo las treinta monedas de su infamia, mientras 
interroga a un ladrón de gallinas. (Huidobro, 1981, p. 116)

La corrupción en la que se viera envuelta la clase política, es la misma que tiene embarrada hasta la balanza de la justicia. Una justicia que es capaz de taparse los ojos por dinero y destaparlos por la falta de éste. Una justicia que discrimina por apellido y por patrimonio, no hace otra cosa que favorecer a aquellos que se roban la patria a pedazos para luego venderla por el mínimo de su precio. Situación, por cierto, que no es exclusiva de esta nación imaginada, como apunta Michel Foucault en La vida de los hombres infames (1996b): "La justicia hace reír cuando es tan indolente que no llega a pronunciar veredicto. Pero es quien reparte la muerte con gesto casi adormecido...” (p. 91). En este caso son los más débiles quienes deben pagar el precio:

Una Justicia tuerta. El ojo que mira a los grandes de la tierra, sellado, lacrado por un peso fuerte y sólo abierto el otro, el que se dirige a los pequeños, a los débiles. Buscáis a los agitadores en el pueblo. No, mil veces, el más grande agitador del pueblo es la Injusticia, eres tú mismo que andas buscando a los agitadores de abajo y olvidas a los de arriba. (Huidobro, 1981, p. 116)

Vicente ve el detonador de una nación desunida e irritada en las injusticias en que se ven envueltos sus connacionales día a día. El dolor de ver a una patria dividida por personas que han abusado de la amabilidad de esta tierra es lo que sulfura a nuestro autor. La gente se ha acostumbrado a vivir a escondidas en las oscuridades, se limita a subsistir como mejor pueda ante el desamparo de una nación que les da la espalda.

Las instituciones como la municipalidad y el Congreso no se quedan fuera de la cuenta pública de Huidobro. Instituciones que debieran estar al servicio de la nación, se transforman en piedras pesadas, símbolos de la ignorancia y la pereza:

Un Congreso que era la feria sin pudicia de la imbecilidad. Un Congreso para hacer onces buenas y discursos malos. Un municipio del cual solo podemos decir que a veces poco ha faltado para que un municipal se llevara en la noche la puerta de la Municipalidad y la cambiase por la puerta de su casa. Si no empeñaron el reloj de la Intendencia y la estatua 
de San Martín, es porque en las agencias pasan poco por artefactos desmesurados. (Huidobro, 1981, p. 117)

Desde los más altos cargos, hasta lo más bajos y cercanos al pueblo se corrompen por el dinero de todos los ciudadanos. Personas poco aptas para ocupar cargos públicos terminan trabajando por sus intereses personales, poco importándole el camino que está tomando el país. En resumidas cuentas, tanto el Ejecutivo, invisible endeble, como el Congreso, ignorante, hampón, y la justicia herramienta o artefacto de los anteriores no acaban más que pervirtiendo el actuar de las capas bajas que terminan siendo juzgadas mientras los verdaderos vándalos infames circulan por los edificios institucionales con la corbata puesta y la cara llena de burla al verse dueños de un micromundo.

\section{D.- La comunidad, sus vicios, sus ambiciones, sus grupos}

Para referirnos a comunidad retomaremos las palabras de Anderson, el cual define el concepto nación como una comunidad política imaginada. Esto nos lleva a plantearnos la nación como una construcción de características que nos hagan sentir parte de la misma región geográfica, región que, por supuesto se creó a raíz de diversos procesos independentistas y de guerra, variando así el margen que conforma esta comunidad. Huidobro, en Balance Patriótico, también nos dirige ciertas palabras a lo que nosotros conocemos como nación:

¡Crisis de hombres! ¡Crisis de Hombres! ¡Crisis de Hombres! Porque, como dice Guerra Junqueiro, una nación no es una tienda, ni un presupuesto una Biblia. De la mera comunión de vientres no resulta una patria, resulta una piara. Socios no es lo mismo que ciudadanos. A1 hablar de Italia decimos: la Italia del Dante, la Italia de Garibaldi, no la Italia de Castagneto, y es que el espíritu cuenta y cuenta por sobre todas las cosas, pues el espíritu eleva el nivel de una nación y de sus compatriotas. (Huidobro, 1981, p. 118)

De algún modo, Huidobro nos instruye sobre cómo se forma una nación, a su parecer. Para el poeta esta comunidad no se gesta por la reunión de gentes que han nacido en el mismo territorio, tampoco por un nivel económico que los lleve a proteger los mismos intereses. Una comunidad, una nación, se conforma por 
los mismos sentires, por las mismas ganas de trabajar en torno a una ilusión en común, y esta siempre debe ser el bienestar de los connacionales. Dejando de lado el término metafórico de alma podemos traducirlo como la pasión y el amor de quienes comparten los mismos sueños de progreso (mayor salud, mejores sueldos, una educación óptima, plenitud, felicidad, paz).

En su afán argumentativo, Huidobro se vale de datos concretos como lo son los porcentajes o cifras preocupantes. Dicha preocupación pasa fundamentalmente por tres líneas: las enfermedades, la falta de educación y los vicios:

El sesenta por ciento de la raza, sifilítica. El noventa por ciento, heredo-alcohólicos (son datos estadísticos precisos); el resto, insulsos y miserables a fuerza de vivir entre la estupidez y las miserias. Sin entusiasmo, sin fe, sin esperanzas. Un pueblo de envidiosos, sordos y pálidos calumniadores, un pueblo que resume todo su anhelo de superación en Cortar las alas a 1 os que quieren elevarse y pasar una plancha de lavandera sobre el espíritu de todo aquel que desnivela el medio estrecho y embrutecido. (Huidobro, 1981, p. 113)

Datos como los anteriores se mantienen ocultos entre festividades nacionales. Huidobro pronuncia verdades insoportables ${ }^{8}$ para el resto de la comunidad letrada. Sin duda, la visión propuesta es negativa y poco auspiciosa, pero sin duda un diagnóstico como este es necesario para provocar un despertar, para provocar movimientos que los lleven a buscar soluciones. Mientras desde la oficialidad la nación intenta enmarcarse en una imagen de inocencia y esfuerzo, aludiendo muchas veces a la utopía de la bondad campesina, Huidobro la sumerge en la envidia y la muestra al mundo sobre una gran montaña de ignorancia.

Nuestro autor a modo de cirujano discrimina aquellas partes del cuerpo-nación enfermas y las enumera con un toque de esperanza propia de un hombre con aires de mesías. Estos vicios son propios de una nación desesperanzada y envidiosa, que lucha a diario por crear un espejismo de sus ideales y de su gente con afán de entrar en el baile luminoso de los países desarrollados. "La envidia o el odio al poder de surgir de un compatriota es uno de los cánceres que posee esta nación". Huidobro añade: "El odio a la superioridad se ha sublimado aquí hasta el paroxismo. Cada ciudadano es un Herodes que quisiera matar en ciernes la luz que se 
levante. Frente a tres o cuatro hombres de talento que posee la República, hay tres millones setecientos mil Herodes" (1981, p. 113). Una sociedad subdesarrollada, que siempre ha debido ver el lujo y la ciencia desde una vitrina inalcanzable, ha crecido envuelta en la desazón y el deseo de tener aquello que no puede poseer.

El texto ensayístico de Vicente Huidobro en una lectura superficial podría darnos cuenta de una mirada cansada y pesimista, un escrito desesperanzador que no ve un avance en la forma de construir y manejar a la nación. Sin duda es un texto que rompe con los mitos fantasiosos que intentaban retratar al país como una potencia entre los países americanos. Pero la verdad es que entre los gritos desgarradores del pequeño dios se deja entrever una esperanza, por ello no se calla y sigue enrostrando los vicios y males. Para poder sanar primero hay que diagnosticar.

La esperanza de nuestro autor recae en las nuevas generaciones, que se escapan a duras penas de las garras de la envidia y de la enviciada forma de dirigir la nación: "El país no tiene más confianza en los viejos, no queremos nada con ellos. Entre ellos, el que no se ha vendido, está esperando que se lo compren" (Huidobro, 1981, p. 119). Las malas costumbres presentes en la clase política, no serán fácilmente erradicadas en una nación que se construyó sobre la base de robos y violencia.

Como la suma de latrocinios de los viejos políticos es ya inconmensurable, que se vayan, que se retiren. Nadie quiere saber más de ellos. Es lo menos que se les puede pedir.

Entre la vieja y la nueva generación, la lucha va a empeñarse sin cuartel. Entre 1os hombres de ayer sin mis ideales que el vientre y el bolsillo, y la juventud que se levanta pidiendo a gritos un Chile nuevo y grande, no hay tregua posible. Que los viejos se vayan a sus casas, no quieran que un día los jóvenes los echen al cementerio. (Huidobro, 1981, p. 120)

Balance Patriótico da cuenta del llanto de una nación que adolece por las malas decisiones de entidades sin escrúpulos, que ha vendido su tierra a pedazos sin tener en cuenta a aquellos que se desviven por tratar de cumplir los viejos sueños esperanzadores que se fijaran en los inicios de la República. 


\section{Notas}

1 Ante las modificaciones políticas, Chile termina sucumbiendo a los vicios de un nuevo sistema económico, de una nueva forma de gobernar y de una nueva manera de administrar. En suma, existe un cambio de papeles en el ámbito político, además de la incursión de nuevos rostros y grupos preparados a tomar el mando del desarrollo de la población. Mario Góngora, en Ensayo histórico sobre la noción del estado en Chile en los siglos XIX y XX (1981), describe este proceso en los siguientes términos: "El Chile anterior a 1891 era vigoroso y rico. Huidobro ha enunciado el mismo sentimiento en el Balance Patriótico al comparar los apellidos 'vinosos' (la vieja aristocracia) con los apellidos 'bancosos' (la nueva plutocracia). La antigua oligarquía cometió muchos errores - dice- - pero no se vendía; la nueva aristocracia de la Banca todo lo cotiza en pesos" (p. 74).

2 Aunque debido al contexto del acontecer nacional, Huidobro, al igual que los políticos de la época, deja afuera de su discurso a los pueblos originarios, no considerándolos como sujeto de derechos.

3 Evidentemente, estamos hablando sobre una época de quiebres políticos que repercuten en el campo intelectual. Huidobro es producto de este quiebre en la política nacional, su prosa surge como respuesta a diversos conflictos que se estaba viviendo en el país y que no estaban siendo resueltos. Lo que ocurre particularmente con el artista en cuestión es apuntado por María Paz Mira en La vanguardia política en Vicente y Huidobro: el paso de una postura estética hacia la militancia política (2008): “[...] el año 1925, marcó un quiebre en la obra del poeta tras la publicación del 'Balance Patriótico' en Acción, diario de purificación nacional. $\mathrm{Su}$ — hasta entonces - poesía creacionista se vio reemplazada por un discurso político mediante el cual se dirigió a la juventud chilena. Discurso que, proyectado sobre la teoría estética literaria del poeta, propuso la ruptura con todo tipo de hegemonía política, social, extranjera o individual. Ya en 1914 con 'Non Serviam' podemos advertir la antesala del 'Balance Patriótico', en donde Huidobro expresó la búsqueda de lo fundamentalmente nacional, instando al individuo a buscar su propio camino, su propia independencia y autonomía" (p. 40).

4 Bernat Castany-Prado (2007), parafraseando al irlandés en una reseña de Comunidades imaginadas, la describe como "una comunidad política que se imagina como inherentemente limitada y como soberana" (p. 2).

5 Recomendamos el artículo "Aproximaciones a la idea de nación: convergencias y ambivalencias de una comunidad imaginada" de Luciana Andrea Mellado (2008). 
6 La actualidad de la reflexión de Huidobro llega a estremecer en algunos pasajes de su Balance, como el que motiva esta nota al pie.

7 La dureza de las expresiones del poeta se hacen presentes nuevamente cuando a este propósito señala: "La historia financiera de Chile se resume en la biografía de unos cuantos señores que asaltaban el erario nacional, como Pancho Falcato asaltaba 4 las casas de una hacienda. Pero aquéllos más cobardes que éste, porque el célebre bandido por lo menos exponía su pellejo" (Huidobro, 1981, p. 116).

8 Locución acuñada por Antonin Artaud al referirse al carácter transgresor, anticipatorio e iluminado de los discursos de sujetos alienados, Van Gogh por ejemplo. Mayores antecedentes en Van Gogh el suicidado por la sociedad (2007).

\section{Referencias bibliográficas}

Alvarado, M. (2010). Ni aristócratas, ni rebeldes, ni tristes ni contentos: escritura y revistas literarias de Joaquín Edwards Bello, Teresa Wilms Montt y Vicente Huidobro. Literatura y Lingüistica, (21), 29-44.

Anderson, B. (1991) [1983]. Comunidades imaginadas. Reflexiones sobre el origen y la difusión del nacionalismo. Ciudad de México: Fondo de Cultura Económica.

Artaud, A. (2007). Van Gogh el suicidado por la sociedad. Buenos Aires: Argonauta.

Castany-Prado, B. (2007): Reseña de Comunidades imaginadas, de Benedict Anderson. Konvergencias, filosofía y culturas en diálogo, (14), 1-16.

Celedón, G. (2013). Precio y desprecio: economía y amor propio. La cañada: pensamiento filosófico chileno, (4), 169-188. Recuperado de: https://dialnet.unirioja.es/servlet/articulo?codigo $=4541263$

Foucault, M. (1996a). Genealogía del racismo. Argentina: Altamira.

Foucault, M. (1996b). La vida de los hombres infames. Argentina: Altamira.

Góngora, M. (1981). Ensayo histórico sobre noción de estado en Chile en los siglos XIX y XX. Santiago: Ediciones La ciudad.

González Cangas, Y. (2002). "Que los viejos se vayan a sus casas”. Juventud y vanguardias en Chile y América Latina. En Feixa, C. \& Costa, C. 
(Comps.). Movimientos juveniles de la globalización a la antiglobalización (pp. 59-91). Barcelona: Ariel.

Huidobro, V. (1981) [1925]. Balance patriótico. En Góngora, M. (Ed.). Ensayo histórico sobre noción de estado en Chile en los siglos XIX y XX (pp. 113-120). Santiago: Ediciones La Ciudad.

Mellado, L. A. (2008). Aproximaciones a la idea de nación: convergencias y ambivalencias de una comunidad imaginada. Alpha, (26), 29-45.

Mira, M. P. (2008). La vanguardia política en Vicente Huidobro: el paso de una postura estética hacia la militancia política. Revista de historia y patrimonio, 1(1), 40-51.

Pinedo, J. (2011). Apuntes para un mapa intelectual de Chile durante el centenario: 1900-1925. América sin nombre, (16), 29-40.

Promis, J. (1977). En torno a la nueva novela hispanoamericana: reubicación de un concepto. Chasqui. Revista de literatura hispanoamericana, 7(1), 925-933.

Renan, E. (2004) [1882]. ¿Qué es una nación? Conferencia dictada en La Sorbo$n a$. Recuperado de http://enp4.unam.mx/amc/libro_munioz_cota/libro/ cap4/lec01_renanqueesunanacion.pdf

Restrepo, E. \& Rojas, A. (2010). Inflexión decolonial. Popayán: Editorial Universidad del Cauca. 